\title{
BMJ Open Modelling the effect of the introduction of antenatal screening for group B Streptococcus (GBS) carriage in the UK
}

\author{
David Bevan, ${ }^{1}$ Alicia White, ${ }^{2}$ John Marshall, ${ }^{\oplus 3}$ Catherine Peckham ${ }^{4}$
}

To cite: Bevan D, White A, Marshall J, et al. Modelling the effect of the introduction of antenatal screening for group B Streptococcus (GBS) carriage in the UK. BMJ Open 2019;9:e024324. doi:10.1136/ bmjopen-2018-024324

- Prepublication history and additional material for this paper are available online. To view these files, please visit the journal online (http://dx.doi. org/10.1136/bmjopen-2018024324).

Received 21 May 2018 Revised 22 0ctober 2018 Accepted 25 January 2019

Check for updates

(c) Author(s) (or their employer(s)) 2019. Re-use permitted under CC BY-NC. No commercial re-use. See rights and permissions. Published by BMJ.

${ }^{1}$ Department of Health and Human Services, Melbourne, Australia

${ }^{2}$ Bazian Ltd, London, UK ${ }^{3}$ UK National Screening Committee, London, UK ${ }^{4}$ Department of Paediatric Epidemiology Unit, University College London, London, UK

Correspondence to John Marshall; John.Marshall@phe.gov.uk

\section{ABSTRACT}

Objectives To estimate the potential impact of the addition of culture-based screening for group $B$ streptococcus (GBS) carriage in pregnancy to a riskbased prevention policy in the UK. We aimed to establish agreement within a multidisciplinary group of key stakeholders on the model input parameters.

Design Deterministic model using a consensus approach for the selection of input parameters.

Setting and participants A theoretical annual cohort of 711999 live births in the UK (excluding births by elective caesarean section).

Interventions Culture-based screening for GBS at 35-37 weeks of pregnancy added to the recommended riskbased prevention policy in place on the date of modelling. Outcome measures Outcomes assessed included use of intrapartum antibiotic prophylaxis (IAP), early onset GBS (EOGBS), EOGBS mortality, severe EOGBS-related morbidity and maternal penicillin anaphylaxis.

Results With no prophylaxis strategy, the model estimated that there would be 421 cases of culture positive EOGBS in a year $(0.59 / 1000$ live births). In the risk-based prophylaxis scenario, 30666 women were estimated to receive IAP and 70 cases of EOGBS were prevented. Addition of screening resulted in a further 96260 women receiving IAP and the prevention of an additional 52 to 57 cases of EOGBS. This resulted in the prevention of three EOGBS deaths and four cases of severe disability. With screening, an additional 1675 to 1854 women receive IAP to prevent one EOGBS case and 24065 to 32087 receive IAP to prevent one EOGBS death.

Conclusions The evidence base available for a broad range of model input parameters was limited, leading to uncertainty in the estimates produced by the model. Where data was limited, the model input parameters were agreed with the multidisciplinary stakeholder group, the first time this has been done to our knowledge. The main impact of screening is likely to be on the large group of low-risk women where the clinical impact of EOGBS tends to be less severe. This model suggests that the reduction in mortality and severe disability due to EOGBS with antenatal GBS screening is likely to be very limited, with a high rate of overdetection and overuse of antibiotics.

\section{INTRODUCTION}

Group B Streptococcus (GBS) is a bacterium which can be commonly found in the digestive system and female reproductive tract. It

\section{Strengths and limitations of this study}

- Model structure and input parameters were agreed to by a multidisciplinary stakeholder group using a consensus building mechanism agreed to in advance.

- Deterministic one-way sensitivity analyses were carried out to assess the impact of changes to key model inputs.

- Systematic review to support each model input was not feasible; data sources were identified through broad systematic searches for recently published evidence. Higher quality evidence, such as systematic reviews, was used where available, as well as national sources including guidance and the UK National Screening Committee's reviews.

- The modelling approach used was pragmatic and deterministic and so it does not provideCls for model outputs.

The evidence base available for many input parameters was limited and this leads to uncertainty in the model's predictions.

can be transmitted from a pregnant carrier to her newborn, typically during vaginal delivery. ${ }^{1}$

While the bacterium does not usually cause harm, in some cases it can cause early onset infection in the newborn's first week of life. This is termed early onset GBS (EOGBS) disease. In the UK, GBS is the most common cause of neonatal sepsis and meningitis. $^{23}$

Comprehensive surveillance established an overall rate of EOGBS at 0.48 per 1000 live births in the UK and Ireland in 2000-2001. ${ }^{4}$ Since then, routine laboratory surveillance has shown a fluctuation in incidence of culture positive EOGBS with slight increases between 2000 and 2010. ${ }^{5}$ Preliminary national surveillance data from 2014 to 2015 suggests that the overall incidence of EOGBS was 0.57 per 1000 live births in the UK and Ireland. ${ }^{6}$ Clindamycin had been used as the main alternative to penicillin prophylaxis in women with penicillin allergy; however, since 2000 there has been a marked increase 
in resistance to clindamycin in patients of all ages. ${ }^{5}$ As a result, the most recent guidance from the Royal College of Obstetricians and Gynaecologists (RCOG), published in 2017, has recommended that clindamycin should no longer be used for this purpose. ${ }^{7}$ Vancomycin is now recommended by the RCOG as the antibiotic of choice for women with severe allergy to penicillin.

In the UK, the mortality rate in term newborns with EOGBS is estimated to be between $6 \%$ and $10.6 \%,{ }^{48}$ with a similar proportion left with severe morbidity. ${ }^{89}$ In pre-term newborns with EOGBS, the mortality rate is reported to be higher. ${ }^{10}$

\section{Antenatal screening for GBS}

Pregnant women can be screened for GBS carriage in late pregnancy. Screening involves the collection of specimens using vaginal and rectal swabs which are processed using selective culture media. ${ }^{11} 12$ The purpose of screening is to identify a group of women who are eligible for intravenous intrapartum antibiotic prophylaxis (IAP) as a means of preventing EOGBS disease. ${ }^{11}$ The mainstay of IAP is benzylpenicillin.

In the UK, currently there is agreement between the guidance issued by the UK National Screening Committee (UK NSG), the National Institute for Health and Care Excellence (NICE) and the RCOG that routine screening for GBS carriage should not be offered. ${ }^{6713}$

A number of maternal risk factors for EOGBS have been identified. These include having a baby with GBS in a previous pregnancy, incidentally detected maternal GBS carriage, prematurity, prolonged membrane rupture and suspected infection in labour. In the UK, at the time of this modelling exercise (2014-2015), GBS IAP was recommended for women with either of the first two listed risk factors and broad spectrum antibiotics, with an agent active against GBS, recommended for women with suspected infection in labour. ${ }^{13}{ }^{14}$ Since the completion of the modelling exercise, the RCOG has updated its guideline on GBS. ${ }^{7}$ The main change is that they now recommend offering GBS IAP to all women in confirmed pre-term labour. This is due to the increased risk of EOGBS and mortality in pre-term infants compared with term infants.

In 2017, the UK NSC completed the process of reviewing the evidence on antenatal GBS screening as part of its triennial review process. ${ }^{15}$ This review concluded that the recommendation not to implement screening in the UK should not be changed. ${ }^{6}$ This was because the committee considered there to be insufficient evidence on the balance of benefits and harms from culture-based screening and treating women with positive results with IAP.

The discussion on antenatal screening for GBS has taken place in a UK policy context shaped by the Maternity Review, ${ }^{16}$ National Health Service Outcomes Frameworks $^{17}$ and the Antimicrobial Resistance Strategy. ${ }^{18}$ These major policy drivers emphasise issues ranging from patient choice and experience, place of birth, reduction of neonatal deaths, antibiotic stewardship and reduction of antibiotic usage. The potential impact of screening on these issues, therefore, needs to be considered.

The charity, Group B Strep Support (GBSS), has campaigned for screening since the 1990s. The controversy surrounding the screening policy is reflected in journal debate, ${ }^{19-22}$ and politicians from the main parties in the four UK countries have signed petitions, raised parliamentary questions and led delegations on this issue. A petition in favour of screening, with over 250000 signatures, was delivered to the ministers and senior officials in January $2017 .^{23}$

In part, this interest is stimulated by the implementation of antenatal screening for maternal GBS carriage in a number of developed countries. With few exceptions, retrospective cohort studies from these countries report a decline in the rate of culture positive EOGBS following the introduction of screening. ${ }^{24}$ For example, surveillance data from the USA reports reduced rates of EOGBS following implementation of each new policy change. ${ }^{11}$ The retrospective and observational design of these studies makes it difficult to ascertain if the data are complete, or if the reduction is conclusively attributable to screening alone. ${ }^{625}$

In addition, the absence of reports on the effect of screening on the rate of culture-negative sepsis presumed to be due to EOGBS disease limits interpretation further. ${ }^{196}$ The difficulty in extrapolating data from different geographical settings has also been noted in relation to EOGBS. ${ }^{27}$ However, the absence of suitably powered UK studies necessitates the use of available data from the UK and other countries, to estimate the potential impact of screening in the UK.

The UK NSC therefore convened a multidisciplinary, multi-agency expert group in 2014 to consider the available evidence to inform the development of a model to estimate the preventive potential of screening when added to current clinical practice. A pivotal aim of the process was to establish a shared set of assumptions among key stakeholders on a controversial topic.

\section{METHODS \\ Model structure}

A pragmatic deterministic model was developed in Microsoft Excel 2010 to simulate two scenarios in a 1-year UK pregnancy cohort. The first scenario was based on the risk-based management pathway recommended in the UK at the time of the model development (20142015). ${ }^{1314}$ The second scenario was the screening and risk-based scenario. In this scenario, antenatal culturebased screening for GBS was offered at 36 weeks of pregnancy to women not already identified as being at risk through the risk-based strategy. This scenario was based broadly on the screening strategy recommended by the US Centers for Disease Control and Prevention ${ }^{11}$ and the existing UK risk-based approach. This meant that women with known risk factors who should already be offered 


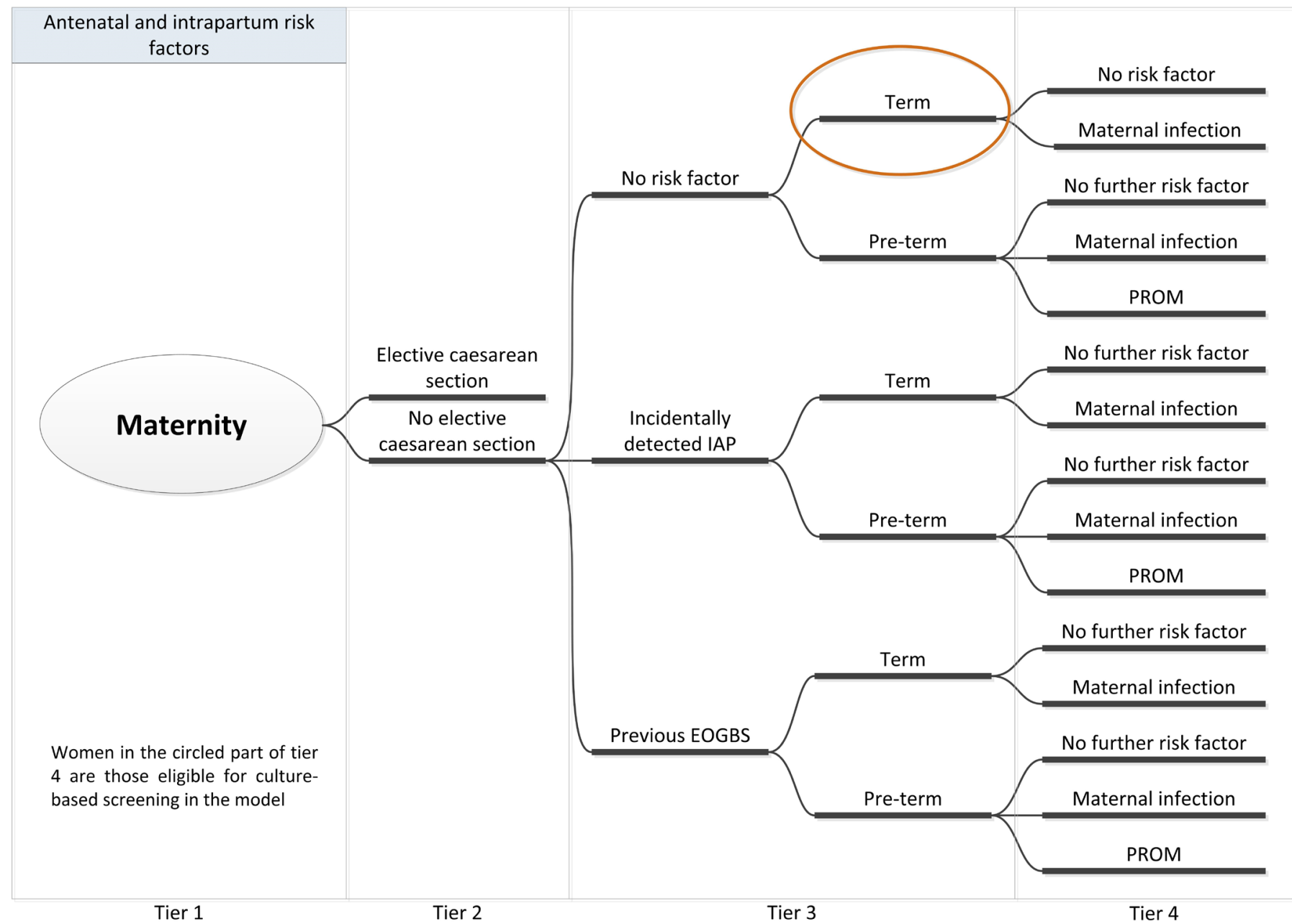

Figure 1 Flow of the maternity cohort into antenatal and intrapartum risk factor groups. EOGBS, early onset GBS; IAP, intrapartum antibiotic prophylaxis; PROM, pre-labour rupture of membranes.

IAP under UK guidelines continued to be offered IAP without screening. Women without these risk factors were offered screening. Women giving birth pre-term, before 37 weeks, were assumed not to receive screening. This was due to the timing of the screening test at 36 weeks and the logistics of transport and laboratory processing time.

Within both scenarios, women were sequentially divided into mutually exclusive groups based on various clinical parameters.

In scenario one, the existing risk-based approach, the clinical characteristics on which the sequential divisions were based were as follows:

- Mode of birth (elective caesarean section or not).

- Presence of antenatal risk factors for EOGBS (a previous baby with EOGBS, incidental detection of GBS carriage or no risk factors).

- Timing of birth (term or pre-term).

- Presence of intrapartum risk factors for EOGBS (pre-term pre-labour rupture of membranes, suspected infection during labour, or 'uncomplicated birth', that is, no intrapartum risk factors).

This resulted in the population being divided into 15 'clinical risk groups'. These are depicted in figure 1.
In scenario 2, the screening and risk-based approach, women who had no antenatal risk factors for EOGBS and who gave birth at term were eligible for screening. The population eligible for screening is depicted in figure 2 and was divided into groups based on:

- Receipt of screening (yes or no).

- Result of screening (positive or negative for GBS).

- GBS status at delivery (positive or negative for GBS).

- Presence of intrapartum risk factors for EOGBS (infection during labour or uncomplicated birth).

This resulted in 23 clinical risk groups in scenario two, comprising the 13 groups from scenario one which would not be eligible for screening plus an additional 10 groups resulting from screening. Risks for EOGBS and related outcomes had been agreed in advance and were applied to these groups to obtain the numbers of affected individuals. The agreed risks are summarised in tables 1 and 2.

Figure 3 depicts the model structure for IAP and outcomes from the model.

To ensure a fair comparison, model outputs were checked to make sure that the number of EOGBS cases was equivalent in both scenarios if no antibiotic prophylaxis was given. In order to achieve this, the GBS 


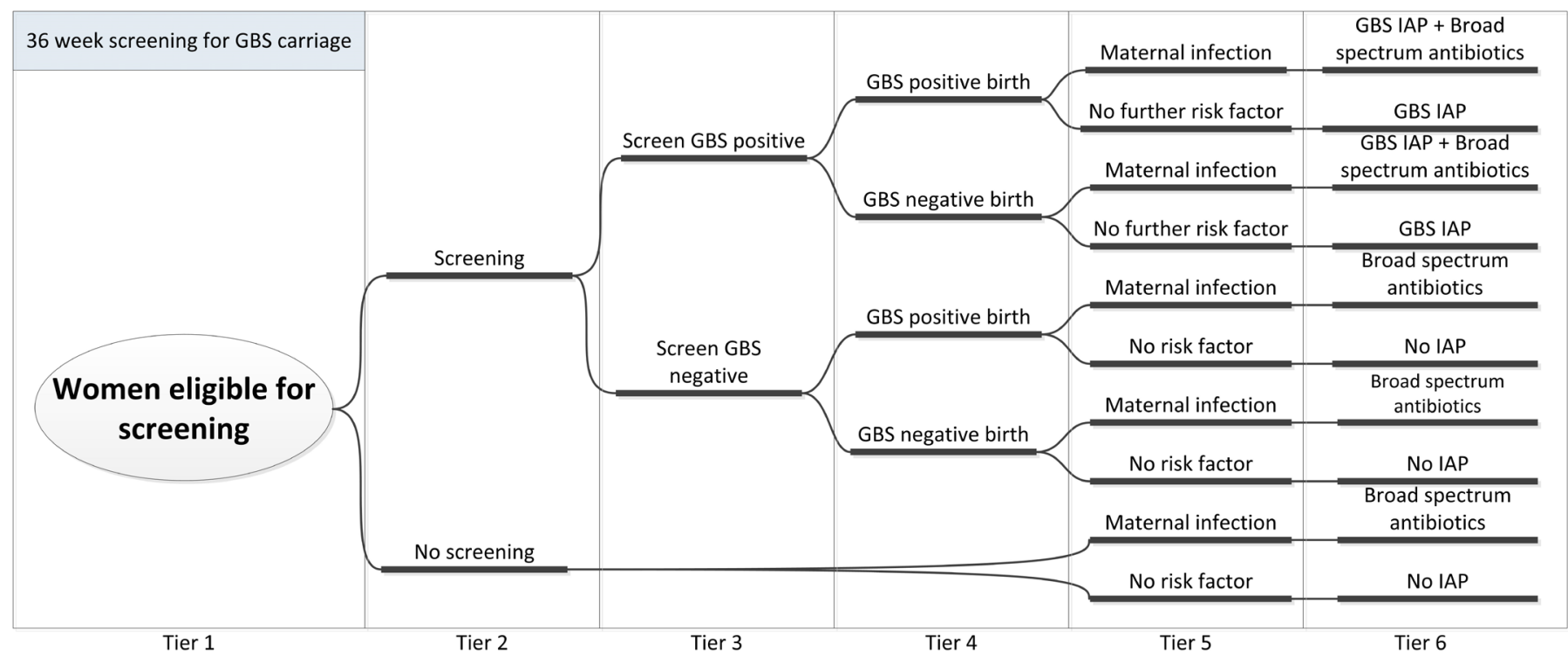

Figure 2 Flow of screening eligible women through the screening scenario. Group B Streptococcus (GBS), intrapartum antibiotic prophylaxis (IAP) against early onset GBS (EOGBS).

colonisation transition rates in the model needed to be adjusted to ensure that there was no overall change in GBS carriage rates between the time of screening and the time of delivery.

\section{Consensus building approach}

Members of the expert group are listed in table 3. They comprised representatives from UK organisations responsible for the development of guidance, policy and patient advocacy relating to EOGBS, as well as experts with experience in clinical practice fields related to EOGBS, microbiology, epidemiology or statistics.

Members of the group were given the opportunity to comment on the structure of the model and individual model parameters.

Evidence identified in the UK NSC's 2012 triennial review of antenatal GBS screening policy and national guidance documents were used to inform data used in the model. ${ }^{6} 131425$ These were supplemented by a broad search in September 2014 for papers published since the 2012 NSC evidence review (see online supplementary information for details). Relevant national data was also identified from sources such as the Office for National Statistics.

Higher quality evidence, such as systematic reviews ${ }^{28} 29$ and randomised clinical trials, were prioritised as sources of data, as were studies from the UK. ${ }^{4}$ A summary of up to five potential values for each input parameter, based on the best available and most relevant evidence identified, was provided to the expert group. Where no evidence regarding an input parameter was identified, this was also noted.

Through a two part survey, the group was asked to consider the relevance of each input parameter, the most appropriate source of the parameter value, and the applicability of the source-study findings to a UK population. Group members could also suggest alternative sources of data. In the absence of suitable published data for a parameter, the expert group selected a figure based on clinical experience and opinion.

All parameters and assumptions that received over $70 \%$ agreement were included in the model unchanged. Those that did not meet this threshold were refined and resubmitted to the expert group. Those that received over $50 \%$ agreement in the second round were included in the model. A small number of assumptions went forward to the second round. These focused on the details of the modelled IAP strategy. This included the timing and duration of IAP, whether second-line antibiotics should be included for analysis in the model, the schedule for those receiving IAP and subsequently developing fever in labour and whether IAP uptake and optimum duration should vary by risk group. All proposed changes received $70 \%$ or more, except for one which received $65 \%$.

The survey results informed two meetings of the expert group. The first meeting reviewed and agreed about the model structure and input parameters. The second received and discussed the outputs of the model.

\section{Patient and public involvement}

Representatives of GBSS were involved as members of the expert group in all stages of the group's work. This included individual discussion with the project lead (DB) regarding the consensus building approach to agreeing to the model's parameters, priorities and outcomes. It also included participation in the two-part survey and workshops to discuss the model.

Results of the model were disseminated to all members of the expert group in the form of a draft report of the modelling project. Comments received from GBSS raised a number of concerns about the outcomes of the model. These concerns centred on the emerging results of an enhanced surveillance study which suggested that the rate of EOGBS had increased 
Table 1 Population characteristics and early onset GBS (EOGBS) mortality and morbidity outcomes

\begin{tabular}{|c|c|c|}
\hline Parameter & Input data & Data source \\
\hline \multicolumn{3}{|l|}{ Maternity population characteristics } \\
\hline Number of live births* & $\begin{array}{l}\text { England and Wales - } 718235 \\
\text { Scotland - } 57202 \\
\text { Northern Ireland - } 24890 \\
\text { Total - } 800327\end{array}$ & $\begin{array}{l}\text { Office for National Statistics } 2012 \text { live birth data } \\
\text { Information Services Division Scotland 2012- } \\
2013 \text { data }^{39} \text { and National Records of Scotland } \\
2012 \text { data }^{40} \\
\text { Northern Ireland Statistics and Research Agency } \\
2012^{41}\end{array}$ \\
\hline Elective caesarean section rate & $\begin{array}{l}\text { England }-10.7 \% \\
\text { Wales }-11.7 \% \\
\text { Scotland }-12.8 \% \\
\text { Northern Ireland - } 15.3 \% \\
\text { Total }-11.04 \%{ }^{*}\end{array}$ & $\begin{array}{l}\text { Hospital Episode Statistics (HES) 2012-2013 } \\
\text { data }{ }^{42} \\
\text { Stats Wales 2012-2013 data } \\
\text { ISD Scotland } 2012-2013 \text { data }^{39} \\
\text { Department of Health, Social Services and Public } \\
\text { Safety Northern Ireland } 2012-2013 \text { data }^{41}\end{array}$ \\
\hline Pre-term birth rate & $8.2 \%$ & HES $2012-2013$ data $^{42}$ \\
\hline
\end{tabular}

Risk factors indicating intrapartum antibiotics in UK guidance

Proportion of the population with antenatal risk factors for EOGBS

$\begin{array}{lll}\text { Previous infant with EOGBS } & 0.03 \% \text { of model cohort } & \text { Colbourn et al, } 2007^{9} \\ \begin{array}{ll}\text { Incidental group B S treptococcus } \\ \text { detection }\end{array} & 5.0 \% \text { of model cohort } & \text { Expert group consensus agreement based on } \\ & & \text { Colbourn et al, 2007 } \text { and Daniels et al, 2011 }^{44}\end{array}$

Proportion of the term population with intrapartum risk factors

Rate of maternal intrapartum infection $2.1 \% \quad$ Daniels et al, $2011^{44}$

in term deliveries

Proportion of the pre-term population with additional intrapartum risk factors

Rate of maternal intrapartum infection $4.1 \% \quad$ Daniels et al, $2011^{44}$

in pre-term deliveries

Rate of pre-labour rupture of $\quad 40 \% \quad$ Royal College of Obstetricians and

membranes (PROM) in pre-term $\quad$ Gynaecologists (RCOG) Pre-term PROM Green-

deliveries

top guideline $44,2010^{45}$

EOGBS mortality and morbidity outcomes

Mortality in pre-term babies with $\quad 18.3 \% \quad$ RCOG, $2012^{14}$ [derived from Heath et al, $2004^{4}$ ]

EOGBS

$\begin{array}{lll}\text { Mortality in term babies with EOGBS } & 5.7 \% & \text { RCOG, } 2012^{14} \text { [derived from Heath et al, 2004 }{ }^{4} \text { ] } \\ \begin{array}{l}\text { Morbidity in pre-term babies with } \\ \begin{array}{l}\text { EOGBS } \\ \text { Morbidity in term babies with EOGBS }\end{array}\end{array} & 6.91 \% & \begin{array}{l}\text { Expert group consensus agreement [based on } \\ \text { Colbourn et al, } 2007^{9} \text { ] }\end{array} \\ & & \begin{array}{l}\text { Expert group consensus agreement [based on } \\ \text { Colbourn et al., 2007 }\end{array}\end{array}$

${ }^{*}$ Excludes stillbirths, miscarriages and terminations; multiple births are only counted once.

and that mortality had decreased. ${ }^{6}$ GBSS suggested that the model should be re-run with the new data and that greater emphasis on EOGBS in term women was needed. It was not possible to address all the concerns without reconvening the expert group in a new modelling exercise. However, GBSS's concern prompted a post hoc analysis in term women with no risk factors indicating IAP. This is the most important group in the context of screening and the post hoc analysis is briefly reported later in this paper.

\section{Outcomes}

Outcomes for each scenario were evaluated in a hypothetical UK maternity cohort, over a 1-year period.
The outcomes were total culture positive EOGBS infections, EOGBS mortality and severe morbidity (eg, severe motor, intellectual, visual, hearing or other neurological impairment that meant the child was not able to attend mainstream school), use of IAP and maternal penicillin anaphylaxis. These outcomes were combined to explore the number of additional women needed to be treated with IAP to prevent additional EOGBS cases, deaths and severe disability.

The expert group noted that some of the model input parameters were based on low quality or inconclusive evidence. In order to explore the effect these data may have on outcomes, one-way sensitivity analyses were 
Table 2 Estimated early onset GBS (EOGBS) incidence rates in each clinical risk group

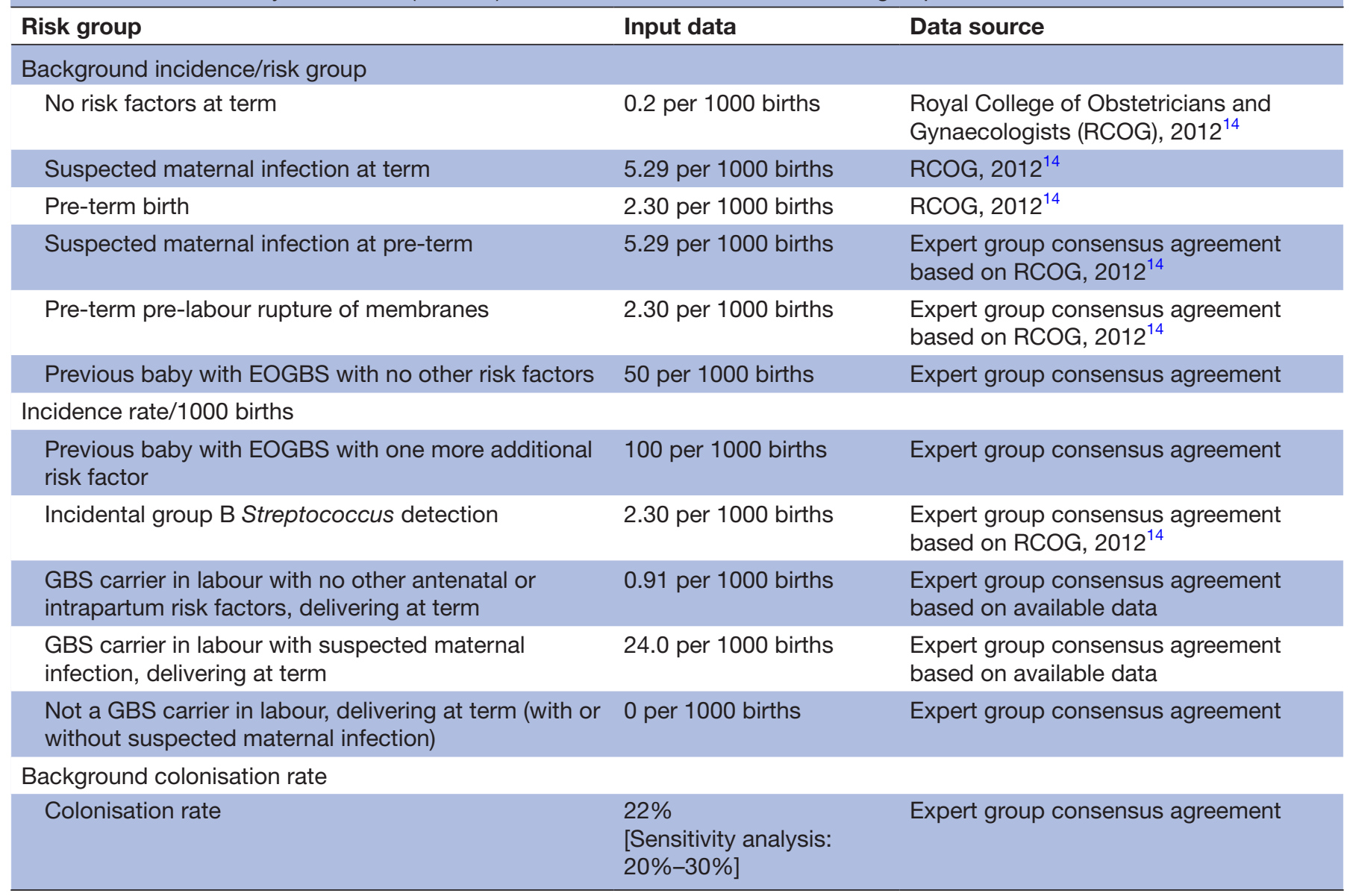

carried out to look at the impact of varying the following input parameters:

- Screening uptake rate.

- Antibiotic delivery in screen positive women.

- Effectiveness of IAP in preventing EOGBS.

- Transition rates for GBS status from screening to delivery.

The sensitivity analyses were run using a plausible lower and higher estimate, based on ranges agreed by the expert group. Individual parameters were changed one at a time, leaving all other parameters unchanged to provide discrete analyses of their impact. Input parameter values and data sources are presented in tables 1, 2, 4 and 5 .

\section{Results}

The model's key results are presented in table 6 .

Based on the inputs 800327 live births were included in the model. Current guidance recommends that women with intact membranes undergoing elective caesarean should not receive GBS IAP in the absence of labour. ${ }^{14}$ As such, live births by elective caesarean were excluded, reducing the number included in the analysis to 711999 . Without IAP, there were an estimated 421 cases of culture positive EOGBS, a rate of $0.59 / 1000$ live births. The modelled estimate of deaths and severe disability caused by EOGBS without IAP was 42 and 29 respectively.
In the risk based scenario, 30666 women were estimated to receive antibiotics in labour and 70 cases of EOGBS prevented. In the screening scenario, a further 96260 women received IAP on the basis of the screening result. This resulted in the prevention of an additional 52 to 57 cases of EOGBS (range in sensitivity analyses: 40 to 67) which included the prevention of three deaths (range in sensitivity analyses: two to four) and four cases of severe disability (range in sensitivity analyses: 3 to 5). This means that with screening, an additional 1675 to 1854 women receive IAP to prevent one EOGBS case and 24065 to 32087 , to prevent one EOGBS death. Maternal anaphylaxis remained an extremely rare event in both scenarios, with 0.3 cases in the risk based scenario and 1.7 cases in the screening scenario.

Among women receiving IAP in the model, $8 \%$ received clindamycin due to reported penicillin allergy. It was assumed that treatment failure due to clindamycin resistance would be avoided by susceptibility testing in screen-positive women.

The sensitivity analyses did not have a large impact on results (see ranges above). An additional, post hoc analysis, focusing on term women with no risk factors indicating IAP, was undertaken. All parameters remained the same as those described above. However, an increase in 
GBS IAP delivery and EOGBS outcomes
Anaphylaxis

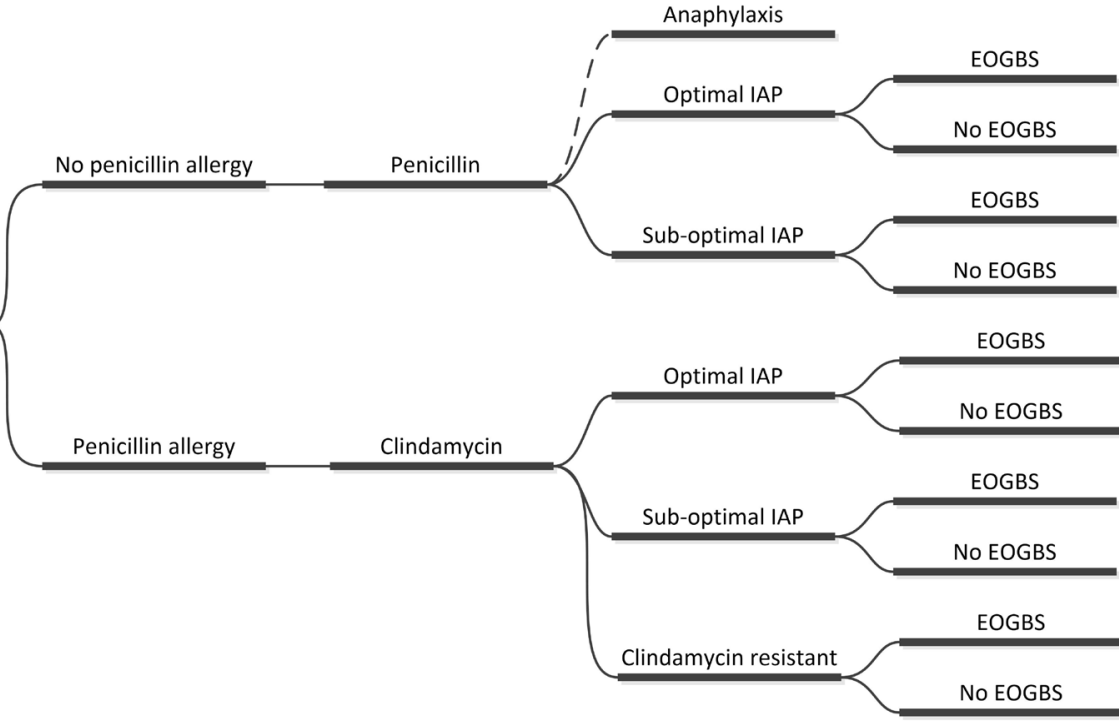

Figure 3 Model structure for women with an indication for intrapartum antibiotic prophylaxis (IAP) and outcomes of babies with early onset GBS (EOGBS).

the rate of EOGBS in carriers in this group along with a decrease in mortality was assumed. When the rate of EOGBS was double that used in the model, the additional number of women receiving IAP to prevent a case of EOGBS was 844 to 926 . The reduced mortality rate meant that the number of women receiving IAP to prevent a death from EOGBS remained the same as the model's main estimate of 24065 to 32087 .

\section{DISCUSSION}

The key outcomes of the model are summarised in box 1 .

This model suggests that the additional reduction in mortality and severe disability due to EOGBS with culturebased screening for maternal GBS carriage added to the current risk-based approach is likely to be, numerically, very limited in the UK. The addition of screening to the modelled risk-based prevention strategy increased the prevention of EOGBS cases from approximately $16 \%$ with the risk-based prevention strategy alone to approximately $25 \%$ of the modelled total. Similarly, the proportion of deaths prevented increased from approximately $12 \%$ to $19 \%$.

There are a number of reasons for this limited numerical impact. The distribution of EOGBS across the risk groups and the clustering of its worst effects in groups outside the screening population limit the benefits that can be expected. In the model, $54 \%$ of the EOGBS cases and $75 \%$ of deaths occurred in groups which were not eligible for screening, notably in the groups of women who already have known risk factors for EOGBS prior to 36 weeks or who give birth pre-term. In addition, not all women carrying GBS at labour would be correctly identified by the test. The model estimated that between 20916 and 30726 women who screened negative at 36 weeks gestation would be GBS positive at delivery. This group comprised women whose GBS carriage status was estimated to change from negative at the point of screening to positive at the time of labour. This number includes women truly transitioning in carriage status and also those receiving false negative screening test results.

Expert consensus and examples of non-UK based screening programmes suggest that attrition along the pathway should be expected and that uptake of both screening and IAP would be less than $100 \%$. In addition, the delivery of IAP for sub-optimum durations is thought to reduce its prophylactic effect and was factored into the model. However, it should be noted that estimates of effectiveness are not well grounded in clinical trial evidence, ${ }^{29}$ and the evidence base exploring duration of administration and prophylactic effect is limited to observational studies. $^{30-32}$

Prevention of EOGBS as a result of screening has to be considered in relation to the impact on the population as a whole. The likelihood of having a baby affected by 
Table 3 Members of the expert group

\begin{tabular}{|c|c|}
\hline Expert group member & Position \\
\hline $\begin{array}{l}\text { Professor Catherine Peckham } \\
\text { (Chair) }\end{array}$ & $\begin{array}{l}\text { National Health Service (NHS), NHS Infectious Diseases in Pregnancy Screening Programme, Executive } \\
\text { Lead/Institute for Child Health }\end{array}$ \\
\hline Professor Peter Brocklehurst & $\begin{array}{l}\text { Director, Birmingham Clinical Trials Unit, University of Birmingham/Royal College of Obstetricians and } \\
\text { Gynaecologists (RCOG) Greentop Guideline }\end{array}$ \\
\hline Professor Androulla Efstratiou & $\begin{array}{l}\text { Head, WHO Global Reference Centre for Diphtheria \& Streptococcal Infections and European Centre for } \\
\text { Disease Prevention and Control, UK Scientific Coordinator }\end{array}$ \\
\hline Professor Paul Heath & $\begin{array}{l}\text { Consultant in paediatric infectious diseases, St George's University of London \& St Georges University } \\
\text { Hospitals NHS Trust, London: BPSU study/RCOG Greentop Guideline }\end{array}$ \\
\hline Dr Rhona Hughes & Obstetrician, Edinburgh/RCOG Greentop Guideline \\
\hline Dr Theresa Lamagni & $\begin{array}{l}\text { Senior Epidemiologist and Section Head, } \\
\text { Healthcare-Associated Infection \& Antimicrobial Resistance Division, National Infection Service, Public } \\
\text { Health England (PHE) }\end{array}$ \\
\hline Mrs Jane Plumb & Chief Executive,GBSS \\
\hline Dr Julie Robotham & Statistics, Modelling and Economics Department, PHE \\
\hline Ms Farah Seedat & PhD student, University of Warwick \\
\hline Dr Nan Shetty & $\begin{array}{l}\text { Consultant Microbiologist and Training Lead, Reference Microbiology Services, } \\
\text { PHE }\end{array}$ \\
\hline Professor Helen Spiby & Professor of Midwifery, University of Nottingham \\
\hline Professor Phillip Steer & Emeritus Professor of Obstetrics \& Gynaecology, Imperial College/GBSS \\
\hline Professor Ben Stenson & Neonatologist, Royal Infirmary of Edinburgh/RCOG Greentop Guideline \\
\hline Professor Mark Turner & Neonatologist, Liverpool Women's NHS Foundation Trust \\
\hline
\end{tabular}

EOGBS appears to be low in women delivering at term with no known risk factors; a rate of about $0.2 / 1,000$ live births was used in the model. These are the women who would be eligible for screening. Studies of antenatal GBS screening test accuracy mainly focus on accuracy for predicting maternal GBS carriage at delivery, and rarely report on neonatal outcomes or ability of the test to predict these. ${ }^{62}$ The positive predictive value of screening in late pregnancy for the outcome of EOGBS has recently been estimated as approximately $0.2 \%$ (2 cases of EOGBS per 1000 screen-detected carriers) ${ }^{6}$ This would be the level of risk reported to women who screen positive. Overdetection is a constant concern about screening, and its high rate in this context means that the ability of GBS screening to provide high quality post-test information may need to be questioned.

Overtreatment is a consequence of overdetection. A number of factors contribute to the high rate of overuse of IAP as a consequence of screening. The model estimated that between 16382 and 24065 screen positive women would receive antibiotics when they are no longer carrying the bacterium during labour. In addition, a large proportion of carriers in labour do not transmit the bacterium to the neonate during delivery. ${ }^{63}$ Among colonised neonates, only $3 \%$ develop EOGBS. ${ }^{34}$

The absence of a diagnostic or risk refinement strategy, to follow a screen-positive result means that many thousands of women would receive GBS IAP to manage a very low risk of EOGBS affecting their baby.

Reports of GBS organisms with reduced susceptibility, or resistance to penicillin, have caused concern despite being very rare and of uncertain clinical significance. ${ }^{511}$ While clindamycin has previously been recommended for IAP in women with penicillin allergy, the increase in resistance to this antibiotic has led to RCOG recommending that it should no longer be used for this purpose. ${ }^{7}$ In addition to this, the possibility has been raised that intrapartum antibiotics may have long-term effects on the infant gut flora and research into this is in the early stages. ${ }^{6}$

The difficulty in quantifying the harm of GBS IAP may make screening appear to be a harm-free intervention. ${ }^{6}$ However, the use of antibiotics in such a large group of women, the vast majority of whom will not experience benefit, means its fit with the current policy emphasis on prudent antibiotic prescribing goals ${ }^{18}$ may be difficult. This is because, as modelled, screening would do little to reduce antibiotic usage in the clinical risk groups who already receive IAP, there is low risk of EOGBS in the screened population, limited impact of screening on the worst outcomes, a lack of evidence to estimate whether outcomes are different for screen-detected and clinically-detected babies with EOGBS and 
Table 4 Antibiotic uptake, optimal and suboptimal delivery, anaphylaxis

\begin{tabular}{|c|c|c|}
\hline Parameter & Input data & Data source \\
\hline \multicolumn{3}{|l|}{ Uptake of antibiotics } \\
\hline Maternal infection at term & $80 \%$ & Expert group consensus agreement \\
\hline $\begin{array}{l}\text { Maternal infection at pre- } \\
\text { term }\end{array}$ & $85 \%$ & Expert group consensus agreement \\
\hline $\begin{array}{l}\text { Pre-term pre-labour rupture } \\
\text { of membranes (pPROM) }\end{array}$ & $5 \%$ & Expert group consensus agreement \\
\hline $\begin{array}{l}\text { Screened group B } \\
\text { Streptococcus (GBS) } \\
\text { positive }\end{array}$ & $\begin{array}{l}80 \% \text { [Sensitivity analysis } \\
70 \%-90 \%]\end{array}$ & $\begin{array}{l}\text { Expert group consensus agreement [based on Albouy-Llaty et } \\
\text { al. } 2012^{46} \text { ] }\end{array}$ \\
\hline $\begin{array}{l}\text { Previous baby with early } \\
\text { onset GBS (EOGBS) }\end{array}$ & $90 \%$ & Expert group consensus agreement \\
\hline $\begin{array}{l}\text { Incidental detection of GBS } \\
\text { carriage }\end{array}$ & $47 \%$ & Moorthy et al, $2014^{47}$ \\
\hline \multicolumn{3}{|l|}{$\begin{array}{l}\text { Optimal and suboptimal } \\
\text { intrapartum antibiotic } \\
\text { prophylaxis (IAP) delivery }\end{array}$} \\
\hline Parameter & $\begin{array}{l}\text { Optimal IAP (delivered } \\
>2 \text { hours) }\end{array}$ & $\begin{array}{l}\text { Suboptimal IAP (delivered } \\
<2 \text { hours) }\end{array}$ \\
\hline
\end{tabular}

Groups treated with antibiotics not solely for prevention of EOGBS

\begin{tabular}{|c|c|c|c|}
\hline Maternal infection at term & $20 \%$ & $80 \%$ & $\begin{array}{l}\text { Expert group consensus } \\
\text { agreement }\end{array}$ \\
\hline $\begin{array}{l}\text { Maternal infection at pre- } \\
\text { term }\end{array}$ & $10 \%$ & $90 \%$ & $\begin{array}{l}\text { Expert group consensus } \\
\text { agreement }\end{array}$ \\
\hline pPROM & $65 \%$ & $35 \%$ & $\begin{array}{l}\text { Expert group consensus } \\
\text { agreement }\end{array}$ \\
\hline \multicolumn{4}{|c|}{ Groups receiving IAP solely for the prevention of EOGBS } \\
\hline Previous baby with EOGBS & $65 \%$ & $35 \%$ & $\begin{array}{l}\text { Expert group consensus } \\
\text { agreement }\end{array}$ \\
\hline $\begin{array}{l}\text { Incidental detection of GBS } \\
\text { carriage }\end{array}$ & $65 \%$ & $35 \%$ & $\begin{array}{l}\text { Expert group consensus } \\
\text { agreement }\end{array}$ \\
\hline \multicolumn{4}{|c|}{ Allergy, resistance and anaphylaxis rates } \\
\hline $\begin{array}{l}\text { Self-reported penicillin } \\
\text { allergy rate }\end{array}$ & $8 \%$ & & $\begin{array}{l}\text { Turrentine et al, } 2009^{48} \text { and } \\
\text { Zilberman et al, } 2014^{49}\end{array}$ \\
\hline Clindamycin resistance rate & $17 \%$ & & $\begin{array}{l}\text { Public Health England , } 2014 \\
(2013 \text { data })^{50}\end{array}$ \\
\hline $\begin{array}{l}\text { Maternal penicillin } \\
\text { anaphylaxis }\end{array}$ & \multicolumn{2}{|l|}{1.56 per 100000 women treated } & Mulla et al, $2010^{51}$ \\
\hline
\end{tabular}

a high rate of overtreatment. In addition, the large number of additional women receiving GBS IAP will need to do so in a setting where the antibiotics can be delivered intravenously. This may reduce the choice of birth setting for these women by removing the option of home birth. 
Table 5 Screening test uptake and colonisation status transitions between screening and delivery

\section{Screening uptake}

\begin{tabular}{|c|c|c|}
\hline Parameter & Input data & Data source \\
\hline Screening uptake rate & $\begin{array}{l}90 \% \\
\text { [Sensitivity analysis - 75\%-95\%] }\end{array}$ & Expert group consensus agreement \\
\hline $\begin{array}{l}\text { 'Transition rate' from group B } \\
\text { Streptococcus (GBS+) at } 36 \text { weeks to } \\
\text { GBS- at delivery* }\end{array}$ & $\begin{array}{l}\text { Base case } 1: 25 \% \\
\text { Base case } 2: 17 \% \\
\text { [Sensitivity analysis } 11.7 \%-40 \% \text { ] }\end{array}$ & $\begin{array}{l}\text { Valkenburg-van den Berg et al. } 2010,28 \\
\text { Di Renzo et al } 2015^{52} \text { and expert group } \\
\text { consensus agreement }\end{array}$ \\
\hline
\end{tabular}

*NB: Based on the data available, it is not possible to distinguish between women who have an incorrect screening result (ie, false positive or false negative) and whose true colonisation status remains unchanged at delivery, and those who had a correct screening result (true positive or true negative) and then transition to a different colonisation status at delivery.

Strengths and limitations

Antenatal screening for GBS is a controversial topic, and one of the strengths of this study was the use of a multidisciplinary stakeholder group encompassing a wide range of viewpoints, to gain consensus on the model structure and inputs. To our knowledge, this is the first

Table 6 Model results

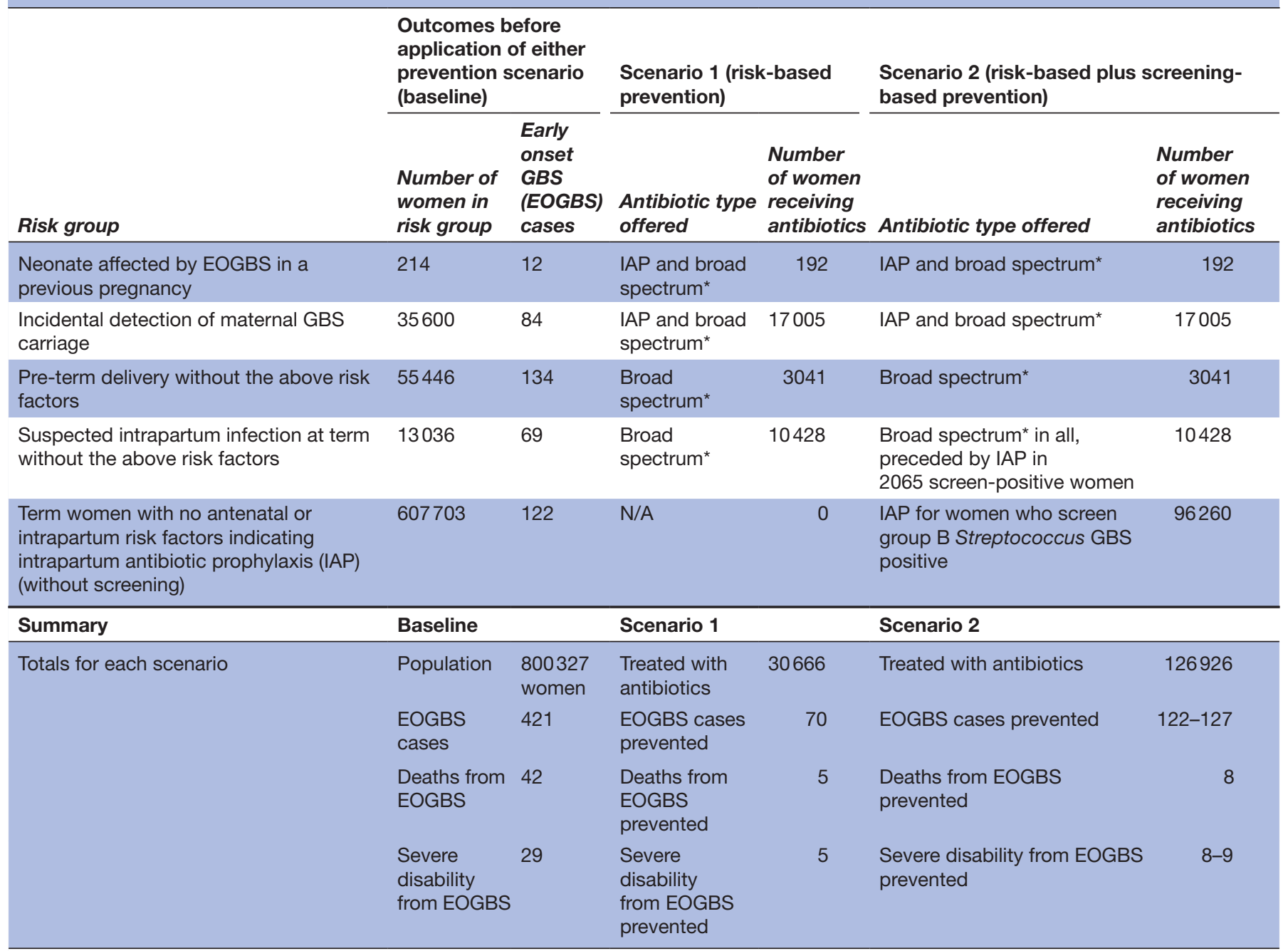

*Broad spectrum antibiotics given to those with suspected intrapartum infection.

N/A, not applicable. 


\section{Box 1 Key outcomes}

\section{Summary information relating to the screening plus risk-} factor scenario

- 558664 women were screened at 36 weeks out of a total of 620739 women. 122906 were screen-positive and 435758 screen-negative. 62075 remained unscreened due to declining the offer or failure to be offered screening.

- The addition of screening at 36 weeks resulted in 96260 women receiving intrapartum antibiotic prophylaxis (IAP) in addition to those already treated within the risk-based strategy alone. Of the screened women, 16382 to 24065 received IAP when they no Ionger carried group B Streptococcus (GBS) at delivery.

- Screening at 36 weeks prevented 52 to 57 cases of early onset GBS (EOGBS), three deaths and four severe morbidities due to EOGBS, in addition to those prevented in the risk-based scenario.

- In the screening-plus-risk -factor scenario, 1675 to 1854 women received penicillin IAP to prevent a case and 24065 to 32087 to prevent a death due to EOGBS, in addition to those prevented in the risk-based scenario

- 2065 screen-positive term women who subsequently developed a suspected infection in labour received GBS IAP in addition to broad spectrum antibiotics. Apart from this group, the number of women receiving antibiotics and the type of antibiotic used remained constant in both strategies in the women with risk factors.

time this approach has been taken to inform a model of antenatal GBS screening.

Data sources were identified through the use of UK National Screening Committee evidence reviews and broad systematic searches for subsequently published evidence. Higher quality evidence, such as published systematic reviews were used where available, as well as national sources including guidance and national statistics. However, systematic reviews to support each model input were not feasible. In addition, the expert group provided input on realistic input values in the absence of relevant evidence.

Limited evidence was available for many model parameters. This includes the rate of penicillin anaphylaxis and the proportion of pregnant women reporting allergy to penicillin. Research to inform these and other inputs would improve future modelling exercises. Research into factors which impact EOGBS risk in babies born to women colonised by GBS could be valuable in the development of a post-screening risk refinement strategy to narrow the pool of women receiving antibiotics.

There is uncertainty regarding the model's outputs due to limitations in the underlying evidence. The results are not dissimilar to those estimated by a hospital in Australia which introduced universal screening. Planned and post hoc sensitivity analyses did not substantially affect this. This Australian study estimated that 1190 women received IAP to prevent one case of EOGBS. ${ }^{35}$ However, it was not clear whether their figure took into account the women who would have received IAP based on the riskbased approach prior to the introduction of screening. In addition, the study was observational and the number of births during the screening period relatively small; so the estimate of EOGBS cases prevented may not have been very robust.

Since the completion of the modelling exercise, there have been changes to the UK's recommended risk-based strategy, mainly that the RCOG has now recommend offering IAP to all women in established pre-term labour. No analysis was undertaken to estimate the effect of these changes. However, this change should not influence the screening scenario, as women who give birth pre-term would not have had the chance to be screened.

The model focused on a limited set of outcomes. In part, this related to the overall aims of the project, which was to try to establish a set of shared assumptions about a core set of basic parameters and outcomes. However, it was also related to the limitations in the data available; for example, it was not considered possible within the terms of this project to model outcomes relating to mild or moderate disability arising from EOGBS.

The model did not explore qualitative questions, for example whether screening would affect maternal choice, the medicalisation of labour or women's experience of maternity services.

\section{CONCLUSION}

This is the first time a consensus-based assessment of the evidence has been developed within a UK-based expert group. A very limited evidence base was encountered and important issues such as the impact of screening on culture-negative disease or on women's birth experience could not be addressed. However, consensus was achieved on the structure of the model and the parameters required for an estimate of the preventive potential of screening.

The resulting outputs focus attention on a hypothetical screening programme which was estimated to combine a low impact, in terms of preventing the worst aspects of EOGBS, with a high impact, in terms of the volume of women categorised as high risk and treated with prophylactic antibiotics in labour.

Expectations about the benefits of interventions, including screening interventions, can be overestimated by both patients and health professionals. ${ }^{36}{ }^{37}$ The modelling work steered by this expert group provides a useful sense of perspective on antenatal screening for maternal GBS carriage.

Acknowledgements We would like to thank all members of the expert group for contributing to this project. We would like to thank representatives of GBSS for their contribution to this project. We would also like to thank Anelia Boshnakova, Senior Information Specialist, Bazian Ltd. who performed the literature searches to identify evidence to inform development of the model.

Contributors The paper is derived from the 'UK National Screening Committee end of project report: Early onset streptococcal (EOGBS) disease: a report of a modelling exercise prepared for the expert group'. The modelling work was steered by an expert group with representation from the relevant professional groups and the major advisory and standard setting bodies and a patient advocacy group. $\mathrm{CP}$ chaired the expert group. The expert group commented on the end of project report, but the preparation of this manuscript was the responsibility of the authors 
alone, and has not been reviewed by the expert group, and may not represent those of all expert group members.DB and JM lead the work to define the model's aims, organise the expert group and to manage the process. AW was responsible for producing the model and provided advice throughout the project's life cycle. $A W$ and $A B$ are employees of Bazian Ltd. which received payment to develop the model through contracts with the UK National Screening Committee.All authors contributed to interpretation of the results. JM, DB, and AW drafted the end of project report and this publication, with critical review by all authors. JM acts as guarantor for the paper.

Funding UK National Screening Committee.

Competing interests $\mathrm{CP}$ chaired the expert group. JM and DB were both employees of the UK National Screening Committee at the time of preparation of the model. AW is an employee of Bazian Ltd. who received payment to develop the model and write up the project through contracts with the UK National Screening Committee. Bazian Ltd. have also been paid to carry out other literature searches, reviews and models for the National Screening Committee, including reviews of the evidence on antenatal GBS screening. Bazian Ltd. is part of The Economist Group, and holds contracts with public and private organisations within the healthcare industry.

Patient consent for publication Not required.

Provenance and peer review Not commissioned; externally peer reviewed.

Data sharing statement No additional data.

Open access This is an open access article distributed in accordance with the Creative Commons Attribution Non Commercial (CC BY-NC 4.0) license, which permits others to distribute, remix, adapt, build upon this work non-commercially, and license their derivative works on different terms, provided the original work is properly cited, appropriate credit is given, any changes made indicated, and the use is non-commercial. See: http://creativecommons.org/licenses/by-nc/4.0/.

\section{REFERENCES}

1. Baker CJ, Barrett FF. Transmission of group B streptococci among parturient women and their neonates. J Pediatr 1973;83:919-25.

2. Vergnano S, Menson E, Kennea N, et al. Neonatal infections in England: the NeonIN surveillance network. Arch Dis Child Fetal Neonatal Ed 2011;96:F9-14.

3. Okike IO, Johnson AP, Henderson KL, et al. Incidence, etiology, and outcome of bacterial meningitis in infants aged $<90$ days in the United kingdom and Republic of Ireland: prospective, enhanced, national population-based surveillance. Clin Infect Dis 2014;59:e150-e7.

4. Heath PT, Balfour G, Weisner AM, et al. Group B streptococcal disease in UK and Irish infants younger than 90 days. Lancet 2004;363:292-4.

5. Lamagni TL, Keshishian C, Efstratiou A, et al. Emerging trends in the epidemiology of invasive group B streptococcal disease in England and Wales, 1991-2010. Clin Infect Dis 2013;57:682-8.

6. UK National Screening Committee. The UK NSC recommendation on Group B Streptococcus screening in pregnancy review of screening. London: Public Health England, 2016.

7. Royal College of Obstetricians and Gynaecologists. Prevention of early-onset neonatal group b streptococcal disease: green-top guideline No. 36. BJOG 2017;124:e280-305.

8. Vergnano S, Embleton N, Collinson A, et al. Missed opportunities for preventing group B streptococcus infection. Arch Dis Child Fetal Neonatal Ed 2010;95:F72-3.

9. Colbourn T, Asseburg C, Bojke L, et al. Prenatal screening and treatment strategies to prevent group B streptococcal and other bacterial infections in early infancy: cost-effectiveness and expected value of information analyses. Health Technol Assess 2007;11:1-226.

10. Hamada S, Vearncombe M, McGeer A, et al. Neonatal group B streptococcal disease: incidence, presentation, and mortality. $J$ Matern Fetal Neonatal Med 2008;21:53-7.

11. Verani JR, McGee L, Schrag SJ. Prevention of perinatal group $B$ streptococcal disease-revised guidelines from CDC, 2010. MMWR Recomm Rep 2010;59:1-36.

12. SMI B 58. Detection of carriage of group B streptococci (Public Health England, 2015. England: SMI B 58.

13. National Institute for Health and Care Excellence. Neonatal infection (early onset): antibiotics for prevention and treatment. CG149. London: National Institute for Health and Care Excellence, 2012.

14. Royal College of Obstetricians and Gynaecologists. The prevention of early-onset neonatal Group B streptococcal disease: Green-top guideline No. 36. 2nd edition. London: Royal College of Obstetricians and Gynaecologists, 2012.

15. UK National Screening Committee. UK NSC: evidence review process. London: Public Health England.

16. National Maternity Review. Better births: improving outcomes of maternity services in England. London: NHS England, 2016.

17. Department of Health. NHS outcomes framework 2015 to 2016. London: Department of Health, 2014.

18. Department of Health. UK 5 Year antimicrobial resistance strategy 2013 to 2018. London: Department of Health, 2013.

19. Brocklehurst P. Screening for Group B streptococcus should be routine in pregnancy: AGAINST: current evidence does not support the introduction of microbiological screening for identifying carriers of Group B streptococcus. BJOG 2015;122:368.

20. Steer PJ. FOR: the case for screening. BJOG 2015;122:369.

21. Plumb J, Clayton G. Group B streptococcus infection: risk and prevention. Pract Midwife 2013;16:27-30.

22. Stewart M, Scamell M, McFarlane A. Professionals respond to GBS article. Pract Midwife 2013;16:8-9.

23. Petition calling for routine group. Petition calling for routine group B Strep tests in the UK goes to parliament. https://www.midirs.org/ group-b-step-tests-uk-parliament/

24. Phares CR, Lynfield R, Farley MM, et al. Epidemiology of invasive group B streptococcal disease in the United States, 1999-2005. JAMA 2008;299:2056-65.

25. Ltd B. Screening for Group B streptococcal infection in pregnancy: external review against programme appraisal criteria for the uk national screening committee. London: UK National Screening Committee, 2012.

26. Carbonell-Estrany X, Figueras-Aloy J, Salcedo-Abizanda S, et al. Probable early-onset group B streptococcal neonatal sepsis: a serious clinical condition related to intrauterine infection. Arch Dis Child Fetal Neonatal Ed 2008;93:F85-9.

27. McQuaid F, Plumb J. More needs to be done to prevent Group B strep infection in the UK. Br J Midwifery 2015;23:418-23.

28. Valkenburg-van den Berg AW, Houtman-Roelofsen RL, Oostvoge $\mathrm{PM}$, et al. Timing of group B streptococcus screening in pregnancy: a systematic review. Gynecol Obstet Invest 2010;69:174-83.

29. Ohlsson A, Shah VS. Intrapartum antibiotics for known maternal Group B streptococcal colonization. Cochrane Database Syst Rev 2014;6:Cd007467.

30. Lin FY, Weisman LE, Azimi P, et al. Assessment of intrapartum antibiotic prophylaxis for the prevention of early-onset group $B$ Streptococcal disease. Pediatr Infect Dis J 2011;30:759-63.

31. Fairlie T, Zell ER, Schrag S. Effectiveness of intrapartum antibiotic prophylaxis for prevention of early-onset group B streptococcal disease. Obstet Gynecol 2013;121:570-7.

32. Illuzzi JL, Bracken MB. Duration of intrapartum prophylaxis for neonatal group B streptococcal disease: a systematic review. Obstet Gynecol 2006;108:1254-65.

33. Daniels J, Gray J, Pattison H, et al. Rapid testing for group B streptococcus during labour: a test accuracy study with evaluation of acceptability and cost-effectiveness. Health Technol Assess 2009;13:1-154

34. Colbourn T, Gilbert R. An overview of the natural history of early onset group B streptococcal disease in the UK. Early Hum Dev 2007;83:149-56.

35. Angstetra D, Ferguson J, Giles WB. Institution of universal screening for Group B streptococcus (GBS) from a risk management protocol results in reduction of early-onset GBS disease in a tertiary obstetric unit. Aust N Z J Obstet Gynaecol 2007;47:378-82.

36. Hoffmann TC, Del Mar C. Clinicians' expectations of the benefits and harms of treatments, screening, and tests: a systematic review. JAMA Intern Med 2017;177:407-19.

37. Hoffmann TC, Del Mar C. Patients' expectations of the benefits and harms of treatments, screening, and tests: a systematic review. JAMA Intern Med 2015;175:274-86.

38. Office for National Statistics. Births in England and Wales. 2012 https://www.ons.gov.uk/peoplepopulationandcommunity/birthsde athsandmarriages/livebirths/bulletins/birthsummarytablesenglandand wales/2013-07-10

39. Information Services Division Scotland. Births in scottish hospitals. 2013 http://www.isdscotland.org/Health-Topics/Maternity-andBirths/Publications/data-tables.asp?id=1285\#1285

40. National Records of Scotland. Births, deaths and other vital events - preliminary annual figures. 2012 https://www.nrscotland gov.uk/statistics-and-data/statistics/statistics-by-theme/vitalevents/general-publications/births-deaths-and-other-vital-eventspreliminary-annual-figures/2012

41. Northern Ireland Statistics and Research Agency. Births in Northern Ireland. Belfast: Northern Ireland Statistics and Research Agency, 
2012. http://webarchive.nationalarchives.gov.uk/20160512114115/ http://www.nisra.gov.uk/archive/demography/publications/births_ deaths/births_2012.pdf

42. Health and Social Care Information Centre. Hospital episode statistics: NHS maternity statistics - England, 2012 - 13. http:// digital.nhs.uk/catalogue/PUB12744

43. Wales $\mathrm{S}$. Number of deliveries in Wales by delivery method and length of stay: 2012-2013. 2015 https://statswales.gov.wales/ Catalogue/Health-and-Social-Care/NHS-Primary-and-CommunityActivity/Maternity/NumberOfDeliveriesInWales-by-DeliveryMethodLengthOfStay

44. Daniels JP, Gray J, Pattison HM, et al. Intrapartum tests for group B streptococcus: accuracy and acceptability of screening. BJOG: An International Journal of Obstetrics and Gynaecology 2011:118:257-65

45. Royal College of Obstetricians and Gynaecologists. Preterm prelabour rupture of membranes: green-top guideline No. 44 London: Royal College of Obstetricians and Gynaecologists, 2010.

46. Albouy-Llaty M, Nadeau C, Descombes E, et al. Improving perinatal Group B streptococcus screening with process indicators. J Eval Clin Pract 2012;18:727-33.
47. Moorthy V, Bakour S, Lawson K. PLD.40 Effective identification and management of Group B streptococcus in pregnancy and labour. Arch Dis Child Fetal Neonatal Ed 2014;99:A117.3-21.

48. Turrentine MA, Ramirez MM, Mastrobattista JM. Costeffectiveness of universal prophylaxis in pregnancy with prior group B streptococci colonization. Infect Dis Obstet Gynecol 2009;2009:1-11.

49. Zilberman D, Williams SF, Kurian R, et al. Does genital tract GBS colonization affect the latency period in patients with preterm premature rupture of membranes not in labor prior to 34 weeks? $J$ Matern Fetal Neonatal Med 2014:27:338-41.

50. Public Health England. Voluntary surveillance of pyogenic and nonpyogenic streptococcal bacteraemia in England, Wales and Northern Ireland: 2013. London: Public Health England, 2014.

51. Mulla ZD, Ebrahim MS, Gonzalez JL. Anaphylaxis in the obstetric patient: analysis of a statewide hospital discharge database. Ann Allergy Asthma Immunol 2010;104:55-9.

52. Di Renzo GC, Melin P, Berardi A, et al. Intrapartum GBS screening and antibiotic prophylaxis: a European consensus conference. $J$ Matern Fetal Neonatal Med 2015;28:766-82. 